\title{
Bloom evenness modulates the influence of bloom abundance on insect community structure in suburban gardens
}

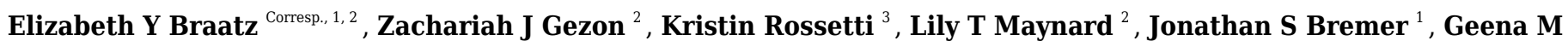
Hill $^{3}$, Marissa A Streifel ${ }^{1}$, Jaret C Daniels ${ }^{3}$

1 Department of Entomology and Nematology, University of Florida, Gainesville, Florida, United States of America

Conservation Department, Disney's Animals, Science and Environment, Lake Buena Vista, Florida, United States of America

3 McGuire Center for Lepidoptera and Biodiversity, Florida Museum of Natural History, Gainesville, Florida, United States of America

Corresponding Author: Elizabeth Y Braatz

Email address: ebraatz@ufl.edu

As land use change drives global insect declines, the value of enhancing habitat in urban and suburban landscapes has become increasingly important for flower-visiting insects. In order to help identify best landscaping practices, we conducted plant surveys and insect bowl-trap surveys in 34 suburban yards for 21 months in Florida, USA, which resulted in 274 paired days of plant and insect survey data. We assessed the impact of nearest greenspace size, distance to greenspace, yard area, plant richness, plant type, bloom abundance, bloom richness, and bloom evenness on insect abundance and richness. Our samples include 34,972 insects captured, 485,827 blooms counted, and 774 species of plants recorded. We found that bloom evenness had a modulating effect on bloom abundance - a more even sample of the same number of blooms would have a disproportionately greater positive impact on flower visitor richness, insect richness, and insect abundance. Bloom abundance was also highly significant and positively associated with flower visitor abundance, but nearest greenspace size, distance to greenspace, plant type (native vs. non-native vs. Florida Friendly), and yard area were not found to be important factors. Plant richness was a highly significant factor, but its effect size was very small. 


\title{
Bloom evenness modulates the influence of bloom abundance on insect community structure in suburban gardens
}

Elizabeth Y. Braatz ${ }^{1,2}$, Zachariah J. Gezon ${ }^{2}$, Kristin Rossetti ${ }^{3}$, Lily T. Maynard ${ }^{2}$, Jonathan S. Bremer $^{3}$, Geena M. Hill ${ }^{3}$, Marissa A Streifel ${ }^{1}$, Jaret C. Daniels ${ }^{1,3}$

1. Department of Entomology and Nematology, University of Florida, Gainesville, FL, USA

2. Conservation Department, Disney’s Animals, Science and Environment, Lake Buena Vista, FL, USA

3. McGuire Center for Lepidoptera and Biodiversity, Florida Museum of Natural History, Gainesville, FL, USA

\section{Corresponding Author: \\ Elizabeth Braatz \\ Steinmetz Hall \\ 1881 Natural Area Dr. \\ Gainesville, FL 32611 \\ Email: ebraatz@ufl.edu}

\begin{abstract}
As land use change drives global insect declines, the value of enhancing habitat in urban and suburban landscapes has become increasingly important for flower-visiting insects. In order to help identify best landscaping practices, we conducted plant surveys and insect bowl-trap surveys in 34 suburban yards for 21 months in Florida, USA, which resulted in 274 paired days of plant and insect survey data. We assessed the impact of nearest greenspace size, distance to greenspace, yard area, plant richness, plant type, bloom abundance, bloom richness, and bloom evenness on insect abundance and richness. Our samples include 34,972 insects captured, 485,827 blooms counted, and 774 species of plants recorded. We found that bloom evenness had a modulating effect on bloom abundance - a more even sample of the same number of blooms would have a disproportionately greater positive impact on flower visitor richness, insect richness, and insect abundance. Bloom abundance was also highly significant and positively associated with flower visitor abundance, but nearest greenspace size, distance to greenspace, plant type (native vs. non-native vs. Florida Friendly), and yard area were not found to be important factors. Plant richness was a highly significant factor, but its effect size was very small.
\end{abstract}


60

61

62

63

64

65

66

67

68

69

70

71

72

73

74

75

76

77

78

79

80

81

82

83

84

85

86

87

88

89

90

91

92

\section{Introduction}

Anthropogenic-driven land use and land cover changes are considered among the primary threats to biodiversity and the fundamental productivity and sustainability of ecological systems (Cardoso et al., 2020; Goulson, 2019; van Klink et al., 2020). Significant biodiversity degradation is often most pronounced in urban areas due to the overall intensity of land modification leading to high levels of direct habitat loss and increased habitat fragmentation (Piano et al., 2020; Sánchez-Bayo and Wyckhuys, 2019). This in turn is commonly associated with the loss of landscape connectivity, changes in species composition, increased biotic homogenization, and the erosion of essential ecosystem services as well as innumerable other stressors and drivers that may negatively affect wildlife. These stressors are reflected in global insect populations, with one recent metastudy finding that terrestrial insect populations have declined by $24 \%$ in the last 30 years (van Klink et al., 2020).

A driving force behind land cover change is urbanization. Today, more than half of the world's people live in urban areas. As global population growth continues to accelerate, some 2.5 billion more people are projected to be added to cities and urban centers by 2050 (United Nations Department of Economic and Social Affairs, 2019). In the United States, over $80 \%$ of the densification of humans and human activities is concentrated in cities, with U.S. developed land area expected to increase by $40-90 \%$ in some locations (Boustan et al., 2013; Sleeter et al., 2017).

While conservation efforts and research have historically focused on more intact, high value natural areas, the utility, role and importance of urban green spaces for biodiversity conservation are increasingly becoming recognized (Rupprecht et al., 2015). Concurrent with urban population growth in the United States, the residential lawn landscape has grown to dominate the suburban and urban landscape. Within this residential landscape, lawns dominate and occupy nearly $40 \%$ of the total estimated $163,812 \mathrm{~km}^{2}$ of turfgrass that covers approximately $1.9 \%$ of the total area of the continental U.S. (Milesi et al. 2005). The non-turfgrass landscaped portion of a typical yard, which includes trees, shrubs, and ornamental plantings, makes up only about $18 \%$ of the total landscape (U.S. Census, 2009). Despite this potential limitation, human-dominated environments can nonetheless be floristically diverse and harbor complex vegetation structure (Sandström et al., 2006; Beninde et al., 2015; Threlfall et al., 2016).

Plant community composition, including the fine scale habitat heterogeneity often seen in urban gardens, has been shown to influence insect community assembly. This has been particularly well-demonstrated for insect groups, with many examples of its predictive or positive correlations (Adams et al. 2020; Baldock et al. 2015, 2019; Theodorou et al. 2017). This close linkage has important ramifications for the development of appropriate conservation strategies to help maintain, increase or restore insect biodiversity in a variety of managed or degraded landscapes, especially with the growing evidence of accelerated insect declines (Potts et al. 2010; Forister et al. 2019; van Klink et al., 2020; Mathiasson and Rehan, 2020). Diverse insect communities are important to ensure the provision of key ecosystem services (i.e. wildlife nutrition, decomposition, natural pest control, and pollination) and promote ecosystem resilience in the face of continued environmental change (Elmqvist et al. 2003). 
93 Understanding which variables within an urban landscape can most impact insect populations is

94 important for conserving insect diversity in home gardens and yards, municipal parks and

95 greenspaces, and other built environments. Efforts to increase insect pollinator and other

96 arthropod assemblages in urban landscapes have often focused on enhancing plant diversity

97 (Campbell et al. 2019), sustained flowering (Williams et al. 2015), floral abundance (Campbell

98 et al., 2007; Campbell et al. 2019), and nativity (Salisbury et al. 2015), or various combinations

99 of these aspects (Vrdoljak et al. 2016). Nonetheless, knowledge gaps remain regarding best

100 management practices for insect communities in urban landscapes. The built environment

101 presents landscape architects, designers, and home gardeners with innumerable plant and design

102 choices while simultaneously conferring constraints related to economics, space, community use,

103 native plant commercial availability, and local covenants, restrictions or ordinances.

104

105

106

In this study, we explored how choices gardeners made in suburban landscape plant community composition influenced the abundance and richness of insects, particularly those known to visit flowers. Our broad hypothesis was: Suburban gardens and yards are habitats for insects. Plant composition in those habitats affects recruitment/presence of wildlife, including insects and pollinators.

With the following sub-hypotheses:

1. Insect and flower visitor richness (number of families) and abundance will increase as the number of species of plants increases

2. For maximum insect abundance and richness, native plants are best, followed by Florida Friendly plants. Non-native plants are the least beneficial for maximizing insect abundance and richness.

3. Insect and flower visitor richness and abundance will increase as the number of blooms increase

The 'Florida Friendly' designation in sub-hypothesis 2 was based on the Florida-Friendly Landscaping ${ }^{\mathrm{TM}}$ Program, which was enacted by the Florida Legislature in 2009 in partnership with University of Florida/IFAS Extension Service, the Florida Department of Environmental Protection, and the five Water Management Districts of Florida (Momol and Tolbert, 2009). This program encourages homeowners to think about their yards' conservation impact and to select plants that have minimal negative impact on the environment. It uses nine criteria centered around watering, pesticides, fertilizers, wildlife habitat, and other issues identified as important through UF/IFAS research efforts (UF/IFAS Florida-Friendly Landscaping Program, n.d.). UF/IFAS has assessed plants as potentially Florida Friendly by using literature-based riskassessment tools and making regular updates to their recommendations as needed.

To answer these questions, we conducted plant and insect biodiversity surveys at 34 separate garden sites in North-Central Florida for two years. Since the gardens were privately owned, we did not manipulate any variables within the sites. We focused on these questions because they involved variables that interested landowners could potentially control in suburban landscapes. 
139 Materials \& Methods

140

141

142

143

144

145

146

147

148

149

150

151

152

153

154

155

156

157

158

159

160

161

162

163

164

165

166

167

168

169

170

171

172

173

174

175

176

177

178

179

180

181

182

183

184

\section{Study sites}

We conducted field portions of study in Alachua County in the North Central region of Florida within and surrounding the city of Gainesville. It is classified as zone 9a on the USDA plant hardiness zone map and as humid subtropical (Cfa) according to the Köppen-Geiger climate classification system (Kottek, et al. 2006).

We studied 34 separate residential urban gardens. Our research was survey-based and our unit of measurement was the entirety of each site's yard. We conducted surveys at the sites over a 21month period from March 2013 - Dec 2014. Access was granted by participating homeowners.

To identify potential study properties, we broadly disseminated a call for study participants by direct email, newsletter posts, and meeting presentations targeting University of Florida IFAS Extension Agents, Master Gardeners, the Sierra Club, the Florida Native Plant Society, the Audubon Society, and the Florida Trail Association. We also used the property address search function on the Alachua County Property Appraiser's website to identify neighborhoods that were viable candidates based on the size and number of eligible parcels, and then reached out to local homeowners associations in those areas (see Supplementary Information: Initial email sent to solicit participants).

Once a homeowner replied, indicating interest and willingness to participate, we verified the parcel size from the Alachua County Property Appraiser's website and conducted a site visit to visually assess the potential property. Homes with swimming pools (which take up a majority of the yard), locked gates, or large dogs on the property that might create access or safety issues were excluded from consideration. We only considered homes with lot sizes between 0.10 to 0.20 hectares. This was considered a conservative range of typical suburban residential lot sizes in Gainesville, Florida. In order to ease the selection process, we did not consider the demographics of garden owners. The homeowners of all selected properties were asked to sign a property access agreement prepared by the University of Florida's Office of the Vice President and General Counsel.

We strove to include properties that varied in composition and structure, so we selected yards that varied in terms of plant richness and nativity. Some yards were more conventional, with a few primarily ornamental, non-native accent plants. Other yards were more naturalistic, with higher abundances and diversity of native and Florida-Friendly Landscaping ${ }^{\text {TM }}$ (FFL) designated species. Each yard varied; we did not have replications of each group along the gradient.

Residential yards were also selected along a gradient of distance to green space. Greenspace was defined as a park, preserve, conservation area/easement, botanical garden, greenway, or undeveloped land. We measured the linear distance from each property to the nearest greenspace using ArcGIS. We noted the log-transformed acreage of the nearest greenspace for each site. Size (square acres) and distance to nearest greenspace were included as separate variables in model testing.

Peer) reviewing PDF | (2020:08:52066:2:0:NEW 20 Feb 2021) 
185 Based on these criteria, we chose 34 residential properties from a pool of over 60 homeowners

186 who indicated interest in participating. Although these sites were not randomly sampled, the

187 number of samples and variance in composition and structure mimics typical suburban to urban

188 gardens around North Central Florida. Once a property was selected, all participants signed a

189 legal release allowing researchers to access their yard as needed. This release detailed the goals

190 and duration of the research study, what researchers would be doing, which types of data would

191 be collected, the frequency and duration of visits, and informed homeowners that they could

192 withdraw their permission/participation at any time (see Supplementary Information:

193 Homeowner Permission to Access Property).

194

\section{Vegetation Survey Protocol}

We conducted two different vegetation surveys for each residential yard: a comprehensive vegetation survey and a flowering plant total bloom count. Exact dates of surveying varied, depending on scheduling and weather. Due to the subtropical climate of our study location, vegetation sampling could be viably conducted on a year-round basis.

We conducted a comprehensive vegetation survey of each residential yard once per year in January 2013 and February 2014. For this, we systematically recorded every plant species in the front and back yard (except for one property where the homeowner elected to only allow their front yard to be surveyed). All plants were identified using floral morphology or non-floral characteristics (e.g., leaf morphology) if the species was not in flower at the time of the survey. Because of the subtropical climate in our study system, most plants were present during these months, though not necessarily blooming. Due to study limitations (labor constraints, minimizing time spent in homeowner backyards) and the logistical considerations of quantifying plant counts for ground covers and vines, we focused our data collection on presence/absence of plant species. Our comprehensive vegetation assessment provided a "baseline" of plant richness and diversity of plant species for each property. Rather than determining exact area coverage for each species, we decided that a bloom count was the most quantifiable way to assess correlations between blooming species and flower visitors.

The second vegetation assessment method was a total bloom count. We recorded each plant species in flower and the corresponding total number of blooms four times per year. We surveyed four times in 2013 (May, July, September, and January) and three times in 2014 (May, July, and September). All flowers were counted on every blooming plant within the yard. We counted individual florets as blooms; consequently, compound flowers counted for multiple blooms. We did this for all species except Asteraceae, which were sampled at the level of the capitulum as in Hicks, et. al. 2016. This method was used to streamline the bloom counting process, which included over 700 species. We collected data for bloom richness and bloom abundance because educational materials for gardeners recommend planting flowers to attract pollinators (UF/IFAS Florida-Friendly Landscaping Program, n.d.; Campbell et al., 2019). While flowers are primarily often planted to attract pollinators, they may also provide valuable habitat to non-pollinating insects. On a biological level, blooms can provide refugia for non-flower visitors, or draw in pollinators for predatory insects to consume (Mahr, 2014). For this reason, we included bloom counts in our models for both flower visiting insects and for total insects. 
231 We identified all plants to the lowest taxonomic level possible, including hybrid species. Field

232

233

234

235

236

237

238

239

240

241

242

243

244

245

246

247

248

249

250

251

252

253

254

255

256

257

258

259

260

261

262

263

264

265

266

267

268

269

270

271

272

273

274

275

276 technicians were provided a simplified plant identification guide. This guide consisted of full color plant pictures along with species names and was developed in consultation with the primary investigator. When a confirmed identification was not possible in the field, we photographed the plant and later verified it in the laboratory. Lab identifications were made using Wunderlin's Vascular Plants of Florida and identification by the primary investigator.

Following taxonomic identification, we subsequently categorized each plant as "Florida Friendly," "Native," or "Non-Native" (including native/non-native variants within a genus). "Florida Friendly" status was based on the Florida-Friendly Landscaping ${ }^{\mathrm{TM}}$ Program. We used the UF/IFAS searchable database of Florida Friendly plants to make this designation. It should also be noted that the Florida Friendly designation includes both native and non-native plants. Plants that were not considered "Florida Friendly" were designated as either Florida native or non-native using the Guide to the Vascular Plants of Florida, 3rd Edition by Richard P. Wunderlin (2003) and the USDA PLANTS database (National Plant Data Team, 2020).

\section{Insect Survey Protocol}

To sample insect abundance and diversity, we deployed pan traps twice per month from March to December in each of the two project years. Exact dates varied among properties due to inclement weather and scheduling factors.

The pan traps each consisted of one $0.35 \mathrm{~L}$ white, blue, red, and yellow plastic bowl. Two traps were deployed per property per insect survey. We placed the first trap in the front yard and the second in the backyard at ground level in open areas. Trap placement was random. We mixed 15 $\mathrm{ml}$ of unscented, uncolored dish detergent per 3.81 L of water and filled each bowl to capacity with the soapy water solution.

Following deployment, all pan traps remained in the field for 24 hours before being collected. During collection, we poured each individual bowl into an 8-12 cup coffee filter set inside a stainless-steel mesh strainer to remove the insect specimens. We placed samples from each bowl in individual sealed plastic bags. All bags were labeled with the property address, date of collection, and bowl color. We subsequently placed all resulting samples in a $-28^{\circ} \mathrm{C}$ freezer for later processing and taxonomic identification. To prepare a sample for insect identification, we removed each bag from the freezer and allowed it to thaw. We gently washed all insect specimens off of the coffee filter and into a labeled vial using a squeeze bottle of ethanol. Once complete, we topped off the vial with additional ethanol.

We used a Leica S6D microscope to identify insects. We identified insects to a family level using Borror and DeLong's Introduction to the Study of Insects and other taxonomic keys (see References for Insect Identifications). Due to time constraints, we did not identify insects to a narrower taxonomic level across both study years. We stored our samples with the Department of Entomology and Nematology at the University of Florida.

We subset our insect data to include a 'flower visiting insect' category. Floral visitors are "organisms that visit flowers for nectar or pollen but may or may not pollinate certain plant 
277 species" (Campbell et al., 2007). We used literature citations to define insects as a flower visitor

278 or non-flower visitor based on records of adult behavior for either all or a portion of a family (see

279 References for Insect Identifications). All bees and lepidopterans were included as flower

280 visitors (except for bee and lepidopteran families without functional mouthparts).

281

282

283

284

285

286

287

288

289

290

291

292

293

294

295

296

297

298

299

300

301

302

303

304

305

306

307

308

309

310

\section{Analyses}

We used $\mathrm{R}$ version 3.6.3 for all analyses ( $\mathrm{R}$ Core Team, 2020). We compared plant survey data to insect survey data. Plant surveys were always conducted within 14 days of an insect survey.

We created general linear mixed models for insect abundance, insect richness, flower-visiting insect abundance, and flower-visiting insect richness using the lme function in R. We square root transformed insect abundance and flower-visiting insect abundance in order to better meet the model assumptions. We accounted for differences between our 34 sites by adding site name and sampling date as random effects.

Our candidate models' explanatory variables included: plant richness (total richness as well as Florida Friendly, native, and non-native plant richness), bloom abundance (total abundance, Florida Friendly, native, and non-native bloom abundance), bloom evenness, bloom richness (total as well as Florida Friendly, native, and non-native bloom richness), site acreage, distance to the closest park, and the log of the acreage of the closest park. We calculated evenness as Evar (Smith and Wilson, 1996). Evar ranges from 0 to 1, where 0 is minimum evenness and 1 is maximum evenness. We checked that our biological explanatory variables (plant richness, bloom abundance) were not correlated to site size, distance to park, or size of nearest greenspace using simple linear regression. We checked that outliers were not driving bloom patterns by removing days with unusually high bloom counts and comparing the results with data that did not have outliers removed. The outliers had no significant effect. Similarly, removing rows of data where evenness $=1.0$ (which is unusual and can also mean a complete absence of blooms) did not change our findings.

We created a list of a priori candidate models with different combinations of potential explanatory variables and then ranked and compared them using the aictab function from the AICcmodavg package.

We generated graphs using the ggplot2 package. To assess the relative strength of different variables, we used the Stats version 6.3.6 package to calculate Pearson's correlation coefficient for each factor in the models (Majewska and Altizer, 2020). In cases when models contained interactions, we graphed the interactions in 3-D using the rms, lattice, and Hmisc packages as in Gezon et al., 2018.

\section{Results}

General characteristics of sampled data

Of the 34 sites selected, average site distance to green space was $1086.9 \mathrm{~m}$, with a range of 0.02 $\mathrm{m}$ to $3039.13 \mathrm{~m}$ and median of $1017.3 \mathrm{~m}$. The log acreage of nearby greenspaces varied from 
3230.30 to 1.76 ha $($ mean $=0.67$ ha, median $=0.40 \mathrm{ha})$, which translates to 0.0000059 to 285.18 ha

$324 \quad($ mean $=0.018$ ha, median $=0.0001 \mathrm{ha})$, while the sites selected ranged from $0.08-0.33$ ha

325 (mean acreage $=0.15$ ha, median $=0.14$ acres).

326

327

328

329

330

331

332

333

334

335

336

337

338

339

340

341

342

343

344

345

346

347

348

349

350

351

352

353

354

355

356

357

358

359

360

361

362

363

364

365

366

367

After 21 months of sampling, we had a total of 247 insect surveys paired with the closest plant survey. Within this dataset, we identified 774 species of plants. Plants were somewhat closely distributed among native, non-native, and Florida Friendly species at 36.7\%, 38.3\%, and 25.0\%, respectively (the percentage is slightly less than $100 \%$ due to a small number of unlabeled plants). Average plant richness was 29.22 plants per garden per survey $(\min =1$, $\max =211$, median $=20$ ). We counted 485,827 blooms. Of these 485,827 blooms, 12 species made up 45\% percent of blooms counted (Fig. 1). Blooms varied by sampling session, with a median of 883.0 blooms, an average of 1,966.9 blooms, and a range of 0 to 21,632 blooms. Bloom evenness averaged 0.24 , with a median of 0.21 and range from 0.04 to 1.00 .

Our insect surveys yielded 34,972 insects. On average 141.6 insects were collected from each garden site per survey (range $=2$ to 540 , median $=124$ ). Insects represented 251 families and five orders (Fig. 2). The family "Dolichopodidae" from the insect survey dataset was superabundant, consisting of almost $50 \%$ of the insect abundance count and creating outliers in the data. However, removing it from the data did not make any difference in the top models, so we kept the family in the final analyses for total insects. Dolichopodidae were not included in analyses for flower visitors as they were not considered flower visitors.

Sub-hypothesis 1: Insect and flower visitor richness (number of species) and abundance will increase as the number of species of plants increases

Counterintuitively, higher plant richness was not associated with higher insect abundance or richness (Tables 1 and 2). Insect abundance and insect richness were both slightly negatively correlated to plant richness.

$\underline{\text { Sub-hypothesis 2: Native plants }>\text { Florida friendly plants }>\text { non-native plants }}$

There was no clear indication that a certain designation of plant type resulted in higher insect abundance or richness (Tables 1 and 2). As seen in the ranked AICc tables in Table 1, we created models that had plant abundance and richness separated by type as well as models that had them not separated. In both cases, total plant richness was included in the models, but plant richness as divided by type was not.

Sub-hypothesis 3: Insect and flower visitor richness and abundance will increase as the number of blooms increase

Blooms were positively correlated to flower visiting insect abundance (Table 2, Fig. 3). While graphs indicated a positive correlation to additional dependent variables, bloom abundance alone was not significant in many of our top models (Table 2). Instead, other models found that bloom evenness had a strong, positive modulating impact on bloom abundance, and bloom evenness*bloom abundance were positive and significant for insect abundance and richness (Fig. 
3684 and Fig. 5). In general, insect abundance and richness increased most when bloom abundance

369

370

371

372

373

374

375

376

377

378

379

380

381

382

383

384

385

386

387

388

389

390

391

392

393

394

395

396

397

398

399

400

401

402

403

404

405

406

407

408

409

410

411

412

413

and bloom evenness both increased (Table 2).

Additional finding: Bloom evenness affected insect abundance and richness

Bloom evenness had a strong, positive modulating effect on bloom abundance for both insect abundance and insect richness (Table 2, Fig. 4 and Fig. 5). In other words, as bloom evenness increased, the same number of blooms had a far larger positive impact on insect abundance and richness than they would have had with an uneven bloom distribution.

\section{$\underline{\text { Non-significant factors }}$}

Plant type (native, non-native, and Florida Friendly plants), distance to green space, and green space size (Table 1) proved to be unimportant, and models that included them were not the top models selected. We accounted for variability between sites by setting site location and date as random effects in all of our mixed models.

\section{Discussion}

Sub-hypothesis 1: Insect and flower visitor richness (number of species) and abundance will increase as the number of species of plants increases

We hypothesized that plant richness would have a large, positive relationship to insect abundance and richness. To our surprise, higher plant richness was slightly negatively associated with total insect abundance and richness. Specifically, our models found plant richness to be significant, but with a weak, slightly negative relationship with insects (Table 2). For flower visiting insects, the top models divided plant richness among Florida Friendly plants, native plants, and non-native plants, but only Florida Friendly plants were significant, and they too were slightly negatively correlated (Table 2).

Other literature notes the unclear nature of the relationship between plant richness and insect populations. Ebeling et al. (2008) mentioned that other field studies have found variable impacts from plant richness on pollinators, but their study, which involved highly controlled test plots, found a strong correlation. Studies by Majewska and Altizer (2020), Ebeling et al. (2008), Haddad et al. (2001), and Wright and Samways (1998) also found a positive relationship.

One possible explanation is that some taxa may be more affected than others. Smith et al. (2006) found that plant richness affected solitary bees and hoverflies, but not solitary wasps or bumblebees. Another potential reason is that all plants are not created equal. Certain plant species may be exceptionally valuable to insects, while other plants have a negligible effect (Ebeling et al., 2008; Frankie et al., 2005). For example, Ebeling et al. (2008) planted 60 unique plant species, but only 32 of them were visited by flower-visiting insects. Of those 32 popular plant species, a single especially attractive species got about half of all insect visits. When plant richness is maximized, perhaps the more attractive plants are diluted by less influential plants.

Peer) reviewing PDF | (2020:08:52066:2:0:NEW 20 Feb 2021) 
414 Because our study was based on observations rather than manipulated experimental plots, it is 415 impossible to completely eliminate confounding factors. Important interactions would likely still 416 appear despite these compounding factors, but moderate to slight factors might get lost.

417 Alternately, perhaps evenness and plant abundance have a relationship. Because our

418 comprehensive vegetation survey only noted the presence or absence of a given plant species, we 419 were unable to collect evenness and plant abundance information for the total plant count, but

420 it's possible that having a number of the same species has a magnifying effect similar to what we 421

422

423

424

425

426

427

428

429

Our study did not find a clear advantage for insect family richness or abundance when planting

430 native, Florida Friendly, or non-native plants. In some cases, our top models simply did not

431

432 include the designations, while in other cases the top models included the designations, but only one (typically the Florida Friendly designation) was statistically significant. This result may

433

434

435

436

437

438

439

440

441

442

443

444

445

446

447

448

449

450

451

452

453 seem surprising, considering the perception that native plants are the superior choice for a variety of reasons, including local adaptation, hardiness, and attractiveness to native pollinators. Our findings provide a valuable finding for home gardeners: existing non-native plants can be beneficial to insects. Our findings are in keeping with the mixed results of other authors (Majweska and Altizer, 2020; Pardee and Philpott, 2014; Smith et al., 2006; Frankie et al., 2005; Haddad et al., 2001; Matteson and Langelloto, 2011; Burghardt and Tallamy, 2015).

On one hand, a study involving 36 experimental plots conducted by Salisbury et al. (2015) found that native and near-native treatments received higher pollinator visits than non-native treatments, and a small study on nectarivorous birds found that of four common plants, the two natives produced higher volumes of nectar per floral unit (French, Major, and Hely 2005). Likewise, Mathiasson and Rehan (2020) found that wild bee declines were linked to introduced plant species. On the other hand, a metastudy on gardener plant selection and maintenance choices by Majewska and Altizer (2020) found that native vs. non-native plant selection did not make a significant difference and recommended follow-up on plant selection. Similarly, a study by Staab et al. (2020) on exotic garden plants found that exotic species helped substitute as food resources for pollinators when native plants became seasonally scarce. The truth may be in the middle. A study by Frankie et al. (2005) found that only $9.5 \%$ of non-native flowers were actually attractive to bees, but those that were attractive were quite beneficial. This may be a piece to the puzzle: exotic flowers overall may not be bad, but simply less likely to provide food resources for flower visiting insects.

454

455

456

457

458

459

While the full answer is still unknown, this does not detract from the other benefits of planting native plants. A large body of literature already exists on the benefits of native plants. Planting hardy, well-suited plants minimizes landowner exposure to fertilizer and pesticides, saves time and money on watering, fertilizers, and pesticides, reduces pollution from runoff, conserves water, controls weeds, reduces erosion, and creates wildlife habitat (UF/IFAS Florida-Friendly

Peer] reviewing PDF | (2020:08:52066:2:0:NEW 20 Feb 2021) 
460 Landscaping ${ }^{\text {TM }}$ Program, n.d., Penn State Extension, 2019). From a research standpoint, more 461 gardening best practices might be found by looking into the effects of host plants on their hosts, 462 expanding on the work of Crowder et al. (2010) and Smith et al. (2006) on predatory and 463 parasitic taxa among native and non-native plants, and expanding research on which plant traits 464 make them more attractive to insects (Ebeling et al., 2008; Grindeland et al., 2005; Akter, Biella, and Klecka, 2017; Ohashi and Yahara, 2001).

Sub-hypothesis 3: Insect and flower visitor richness and abundance will increase as the number of blooms increase

Bloom abundance had a strong positive effect on flower-visiting insect abundance. This is in agreement with most literature (Majewska and Altizer; 2020, Ebeling et al., 2008; Pardee and Philpott, 2014; Akter et al., 2017; Matteson and Langelloto, 2011). The strength of the interaction, measured by Pearson's correlation coefficient $r$, was similar to Majewska and Altizer (2020), who found that flower abundance had a positive effect on insects with an effect size of 0.26 (compared to 0.296 for our study).

Additional finding: Bloom evenness affected insect abundance and richness

While bloom abundance was important alone, bloom evenness proved to have a surprisingly influential role, strongly modulating the effects of bloom abundance in the top models for Insect Abundance and Insect Richness and appearing in the top three models for Flower-visiting Insect Abundance and Richness. As seen in Figs. 4, 5, and 6, as bloom abundance increased, insect richness and insect abundance also increased modestly. However, when bloom abundance increased in conjunction with increased bloom evenness, insect richness and abundance increased dramatically.

Insects benefited most from a plant community that had both abundant and evenly distributed floral resources. Flower visitor richness and, even more dramatically, total insect abundance, increased most when more flowers were present with consistently represented blooming plants.

490 It should be noted that complete evenness (Evar $=1.0)$ was not needed to benefit insects. Our focal properties had bloom evenness values primarily between 0.1596 and 0.2581 . However, when blooms approached a near-monoculture, Evar values tended to be very low. Nearmonocultures seemed to reduce the effectiveness of high bloom counts; thus it appears that some family richness is still an important consideration for landscapes.

Our results regarding evenness help fill critical knowledge gaps on the best practices for benefiting insects in urban landscapes. Very few studies on urban and suburban insect biodiversity have focused on evenness. Stavert et al. (2019) found that evenness by itself did not have a huge impact, but it indirectly affected plant reproduction by affecting the structure of plant-pollinator networks. Our own results on evenness by itself were negligible, but the interaction between evenness and abundance indicated a potentially interesting, statistically significant relationship. Additional research on the bloom abundance / evenness interaction could potentially maximize valuable ecosystem services such as pest control and pollination. 
506

507

508

509

510

511

512

513

514

515

516

517

518

519

520

521

522

523

524

525

526

527

528

529

530

531

532

533

534

535

536

537

538

539

540

541

542

543

544

545

546

547

548

549

550
2017; Southon et al., 2017; Li et al., 2017; Todorova, Asakawa, and Aikoh, 2004). When selecting plants, ensuring that different species of flowering plants will provide an even bloom presence could be a low-hanging fruit to increase the impact of plant species purchased.

Restoration projects would also benefit from increased investigation into the impact of community evenness. Restoration projects already emphasize diversity and native plant selection (Bischoff, Steinger, and Müller-Schärer, 2010; Richards, Chambers, and Ross, 1998; Stanley, Kaye, and Dunwiddie, 2011). This approach has been successful, with Bischoff, Steinger, and Müller-Schärer (2010) finding that high genetic diversity resulted in more productive plant populations with less risk of failing to establish. Observational studies on bloom evenness and bloom abundance could provide another metric for evaluating these projects. If an interaction is found, future restorations could maximize impact by prioritizing not just the total number of blooming plant species introduced, but also ensuring that the numbers planted provide an even spread of available resources. Furthermore, insects are seldom considered with habitat restoration projects and methods that include measuring evenness could assist in combatting insect and pollinator declines.

\section{On the study location}

Our study helps fill a literature gap on urban and suburban biodiversity in the Southeast United States. Most studies on urban garden habitat features and insects have been in mild to cold midlatitude climates (Majewska and Altizer, 2020; Ebeling et al., 2008; Frankie et al., 2005; Matteson and Langelloto, 2011; Pardee and Philpott, 2014; Philpott et al., 2014; Smith et al., 2006). Our study took place in Florida, which has a humid subtropical climate (Cfa) (Kottek et al., 2006). The differences in seasonality may be significant. Most temperate climates have distinct seasons, and many plants and animals go into diapause or die off each winter (Powell and Logan, 2005). By contrast, our study site was primarily affected by two periods of growth dictated by rainy and dry seasons. This difference in seasonality resulted in differences between bloom periods and insect activity (Wolda, 1988; Lechowicz, 1995; Shimadzu, 1998). This in turn may have affected plant availability, resulting in a larger plant pool for homeowners to select.

\section{$\underline{\text { Insignificant factors }}$}

Contrary to our expectations, distance to green space and the size of the nearest green space did not influence the population of flower-visiting insects. Majewska and Altizer (2020) found that many studies identified a correlation between distance to various habitats and green space, but studies have also found that that landscape level factors tended to have weaker associations with insects than within-garden features (Majewska and Altizer, 2020; Philpott et al., 2014; Pardee and Philpott, 2014; Williams and Winfree, 2013). For example, Majewska and Altizer (2020) and Philpott et al. (2014) found that landscape level factors (such as distance to agriculture, distance to water, or distance to forest) were relevant, but tended to have weaker associations with pollinators than within-garden features. In other words, external factors beyond one's control, such as the size of the nearest park, are less important than the choices one makes with plant selection.

Peer) reviewing PDF | (2020:08:52066:2:0:NEW 20 Feb 2021) 
551 We also found that site size did not influence insects. However, as we selected suburban lots

552 within a set range of sizes these conclusions are quite limited. By contrast, Majewska and Altizer

553 (2020) found garden size was important for insects. This difference in findings reveals an

554 opportunity for future research to explore larger datasets with a range of yard sizes. Yet, our

555 findings provide encouraging support for the impact homeowners can have with the factors they

556

557

558

559

560

561

562

563

564

565

566

567

568

569

570

571

572

573

574

575

576

577

578

579

580

581

582

583

584

585

586

587

588

589

590

591

592

593

594 have control over in their yards, as yard size is less flexible or easy to change.

\section{Limitations}

There were some limitations to our study regarding plant abundance, timing, trap types, and species identifications. We did not include plant species abundance because our baseline vegetation surveys only recorded presence/absence of a given species and our bloom surveys did not include plant abundance counts. Thus, our vegetation surveys yielded only total plant richness and total bloom abundance. Ideally, we would have had time to also include data collection on plant abundance.

We were also limited by scheduling logistics: ideally, the insect and vegetation surveys should be collected on the same day. However, we conducted our insect and vegetation surveys on different days and then matched our insect surveys to the closest vegetation sampling day. Since most of the plants in our study bloomed for more than two weeks (UF/IFAS, n.d.), we feel confident that we still got an accurate assessment of what plants were blooming around when we collected insects, but same-day surveys would have been preferrable.

We also only used bowl traps for insect surveys due to the use of homeowners' private properties. These were deemed sufficient for the study since bowl traps are a widely known, widely recommended, and effective method for sampling flower visitors (Grundel et al., 2011; O'Connor et al., 2019; Westphal et al., 2008). Nonetheless, we may have been able to capture more insects with a wider array of techniques, such as malaise traps or sweep netting. We also did not account for the following variables: bare ground, water sources, unmowed areas, canopy cover, and pesticide applications.

Another limitation that would have added to the study was identifying insects to species level. Due to the volume of insects collected and labor available, we only identified insects to the family level across both years. This allowed us to identify flower visiting insects and general trends across families and orders. However, species richness is the more commonly used metric, and we were not able to determine which flower visiting insects were native, an important subclassification. Native pollinators have experienced severe declines over the past several decades, and there is great interest (among both the public as well as scientific communities) and value in finding which variables will most help native pollinators (Potts et al. 2010; Forister et al. 2019; van Klink et al., 2020; Mathiasson and Rehan, 2020). Future studies of plant-pollinator interactions could benefit by identifying insect flower visitors to a lower taxonomic level.

\section{Conclusions}

595 
596 Insect populations are declining globally (Cardoso et al., 2020; van Klink et al., 2020). We 597 conducted this study with the goal of increasing our understanding of which suburban landscape 598 factors contribute most to attracting pollinator and insect populations in order to help inform 599 plant choice and related landscaping decisions.

600

601

We found that homeowners can enhance the insect richness of their backyard habitats by

602

603

604

605

606

607

608

609

610 planting more blooming plants with an even selection of species. More blooms were clearly associated with more flower visitors, and the evenness of the blooms significantly modulated the effectiveness of bloom abundance. Planting even, abundant flowering plants of diverse species will have a much greater impact on attracting insects than planting the same number of just one species. Very few studies on urban insect biodiversity have focused on evenness, so finding that the two were related expands the literature on this topic. Our results have the potential to be applied more broadly to other landscapes within the built environment by landscape architects, urban planners, and land managers.

612

Native, non-native, and Florida Friendly plant designations were not important in this study.

613 Although the best fit models found no clear distinction between these three types of plants, other

614

615 benefits of native landscaping remain substantial. Instead, gardeners can conclude that their existing non-native plants may still provide vital resources to flower visiting insects.

Our study highlighted opportunities for additional research. Our study was not focused on a scale to enable comparisons between individual plant taxa. Future studies might result in flower

618

619 abundance guides to help decision makers find the ideal plant abundance and distribution. Likewise, both our findings and literature on plant richness were unclear. An interaction term between plant abundance and evenness may exist that explains the variable effects of plant richness.

624

625

When a suburban homeowner sets out to augment or landscape their yard there are many limiting factors they must consider, as well as factors out of their control. We found that two factors under their control- choosing flowering plants and planting even numbers of these plants- were more influential than other external factors such as nearby greenspaces. Specifically, we found that when bloom abundance and evenness increased simultaneously, there were positive, non-

628

629

630 additive effects on flower-visiting insects. The results of our study show that homeowners can make simple changes to their landscaping decisions that will dramatically increase the impact on

631 flower-visiting insects without an increase in cost or labor.

632

633

634

635

636

637

638

639

640

\section{Funding}

This research was funded by a grant from the Florida Wildflower Foundation (UF contract No. 00084425).

641

\section{Acknowledgements}


642 We are grateful to the Florida Wildflower foundation, whose generous grant supported this study

643 and inspired our topic. We would like to thank the many homeowners who voluntarily

644 participated in the study and the research technicians (J. Akers Pence, Erica Porter, and Liana

645 Teigen) who conducted the plant and insect surveys. We thank Sandy Koi for her assistance in

646 recruiting and coordinating study participant volunteers, and Joshua Campbell and Chase

647 Kimmel for compiling a comprehensive literature-based reference for categorizing insects as

648 flower visitors. We would additionally like to thank the Florida Wildflower Foundation, Florida

649 Association of Native Nurseries, Florida Native Plant Society, Sierra Club, and the Florida-

650 Friendly Landscaping ${ }^{\mathrm{TM}}$ Program for helping advertise the request for research program

651 homeowner volunteers, and the University of Florida's Office of the Vice President and General

652 Counsel for finalizing the Homeowner Permission to Access Property agreement. This research

653 would not be possible without them. We would also like to thank the Conservation Team at

654 Disney's Animal Kingdom ${ }^{\circledR}$ and the Braatz family for their support throughout Elizabeth

655 Braatz's graduate program.

656

657

658

659

\section{References}

660

661

Adams BJ, Li E, Bahlai CA, Meineke EK, McGlynn TP, Brown BV. 2020. Local- and

662

663

664

665

666

667

668

669

670

671

672

673

674

675

676

677

678

679

680

681

682

683

684 landscape-scale variables shape insect diversity in an urban biodiversity hot spot. Ecological Applications 30:e02089. DOI: 10.1002/eap.2089.

Akter A, Biella P, Klecka J. 2017. Effects of small-scale clustering of flowers on pollinator foraging behaviour and flower visitation rate. PLOS ONE 12:e187976. DOI: 10.1371/journal.pone.0187976.

Baldock KCR, Goddard MA, Hicks DM, Kunin WE, Mitschunas N, Morse H, Osgathorpe LM, Potts SG, Robertson KM, Scott AV, Staniczenko PPA, Stone GN, Vaughan IP, Memmott J. 2019. A systems approach reveals urban pollinator hotspots and conservation opportunities. Nature Ecology \& Evolution 3:363-373. DOI: 10.1038/s41559-018-0769-y.

Baldock K, Goddard M, Hicks DM, Kunin W, Mitschunas N, Osgathorpe L, Potts S, Robertson K, Scott A, Stone G, Vaughan I, Memmott J. 2015. Where is the UK's pollinator biodiversity? The importance of urban areas for flower-visiting insects. Proceedings of the Royal Society B: Biological Sciences 282. DOI: 10.1098/rspb.2014.2849.

Bellamy CC, van der Jagt APN, Barbour S, Smith M, Moseley D. 2017. A spatial framework for targeting urban planning for pollinators and people with local stakeholders: A route to healthy, blossoming communities? Environmental Research 158:255-268. DOI: 10.1016/j.envres.2017.06.023.

Beninde J, Veith M, Hochkirch A. 2015. Biodiversity in cities needs space: a meta-analysis of factors determining intra-urban biodiversity variation. Ecology Letters 18:581-592. DOI: 10.1111/ele.12427.

Bischoff A, Steinger T, Müller-Schärer H. 2010. The Importance of Plant Provenance and Genotypic Diversity of Seed Material Used for Ecological Restoration. Restoration Ecology 18:338-348. DOI: 10.1111/j.1526-100X.2008.00454.x. 
685 Boustan LP, Bunten DM, Hearey O. 2013. Urbanization in the United States, 1800-2000. National Bureau of Economic Research. DOI: 10.3386/w19041.

687

688

689

690

691

692

693

694

695

696

697

698

699

700

701

702

703

704

705

706

707

708

709

710

711

712

713

714

715

716

717

718

719

720

721

722

723

724

Burghardt KT, Tallamy DW. 2015. Not all non-natives are equally unequal: reductions in herbivore $\beta$-diversity depend on phylogenetic similarity to native plant community. Ecology Letters 18:1087-1098. DOI: 10.1111/ele.12492.

Campbell JW, Hanula JL, Waldrop TA. 2007. Effects of prescribed fire and fire surrogates on floral visiting insects of the blue ridge province in North Carolina. Biological Conservation 134:393-404. DOI: 10.1016/j.biocon.2006.08.029.

Campbell JW, Kimmel CB, Grodsky SM, Smithers C, Daniels JC, Ellis JD. 2019. Wildflower plantings harbor increased arthropod richness and abundance within agricultural areas in Florida (USA). Ecosphere 10:e02890. DOI: 10.1002/ecs2.2890.

Cardoso P, Barton PS, Birkhofer K, Chichorro F, Deacon C, Fartmann T, Fukushima CS, Gaigher R, Habel JC, Hallmann CA, Hill MJ, Hochkirch A, Kwak ML, Mammola S, Ari Noriega J, Orfinger AB, Pedraza F, Pryke JS, Roque FO, Settele J, Simaika JP, Stork NE, Suhling F, Vorster C, Samways MJ. 2020. Scientists' warning to humanity on insect extinctions. Biological Conservation 242:108426. DOI: 10.1016/j.biocon.2020.108426.

Crowder DW, Northfield TD, Strand MR, Snyder WE. 2010. Organic agriculture promotes evenness and natural pest control. Nature 466:109-112. DOI: 10.1038/nature09183.

Ebeling A, Klein A-M, Schumacher J, Weisser WW, Tscharntke T. 2008. How does plant richness affect pollinator richness and temporal stability of flower visits? Oikos 117:18081815. DOI: $10.1111 / \mathrm{j} .1600-0706.2008 .16819 . x$.

Elmqvist T, Folke C, Nyström M, Peterson G, Bengtsson J, Walker B, Norberg J. 2003. Response diversity, ecosystem change, and resilience. Frontiers in Ecology and the Environment 1:488-494. DOI: 10.1890/1540-9295(2003)001[0488:RDECAR]2.0.CO;2.

Forister ML, Pelton EM, Black SH. 2019. Declines in insect abundance and diversity: We know enough to act now. Conservation Science and Practice 1:e80. DOI: 10.1111/csp2.80.

Frankie GW, Thorp RW, Schindler M, Hernandez J, Ertter B, Rizzardi M. 2005. Ecological Patterns of Bees and Their Host Ornamental Flowers in Two Northern California Cities. Journal of the Kansas Entomological Society 78:227-246. DOI: 10.2317/0407.08.1.

French K, Major R, Hely K. 2005. Use of native and exotic garden plants by suburban nectarivorous birds. Biological Conservation 121:545-559. DOI:

10.1016/j.biocon.2004.06.004.

Gezon ZJ, Lindborg RJ, Savage A, Daniels JC. 2018. Drifting Phenologies Cause Reduced Seasonality of Butterflies in Response to Increasing Temperatures. Insects 9:174. DOI: 10.3390/insects 9040174 .

Goulson D. 2019. The insect apocalypse, and why it matters. Current Biology 29:R967-R971. DOI: $10.1016 /$ j.cub.2019.06.069.

Grindeland JM, Sletvold N, Ims RA. 2005. Effects of floral display size and plant density on pollinator visitation rate in a natural population of Digitalis purpurea. Functional Ecology 19:383-390. DOI: $10.1111 / j .1365-2435.2005 .00988 . x$.

PeerJ reviewing PDF | (2020:08:52066:2:0:NEW 20 Feb 2021) 
725 Grundel R, Frohnapple KJ, Jean RP, Pavlovic NB. 2011. Effectiveness of Bowl Trapping and

726

727

728

729

730

731

732

733

734

735

736

737

738

739

740

741

742

743

744

745

746

747

748

749

750

751

752

753

754

755

756

757

758

759

760

761

762

763

764

Netting for Inventory of a Bee Community. Environmental Entomology 40:374-380. DOI: 10.1603/EN09278.

Haddad NM, Tilman D, Haarstad J, Ritchie M, Knops JMH. 2001. Contrasting Effects of Plant Richness and Composition on Insect Communities: A Field Experiment. The American Naturalist 158:17-35. DOI: 10.1086/320866.

Hicks DM, Ouvrard P, Baldock KCR, Baude M, Goddard MA, Kunin WE, Mitschunas N, Memmott J, Morse H, Nikolitsi M, Osgathorpe LM, Potts SG, Robertson KM, Scott AV, Sinclair F, Westbury DB, Stone GN. 2016. Food for Pollinators: Quantifying the Nectar and Pollen Resources of Urban Flower Meadows. PLOS ONE 11:e0158117. DOI:

10.1371/journal.pone.0158117.

van Klink R, Bowler D, Gongalsky K, Swengel A, Gentile A, Chase J. 2020.Meta-analysis reveals declines in terrestrial but increases in freshwater insect abundances. Available at https://pubmed.ncbi.nlm.nih.gov/32327596/ (accessed August 3, 2020). DOI: 10.1126/science.aax9931.

Kottek M, Grieser J, Beck C, Rudolf B, Rubel F. 2006. World Map of the Köppen-Geiger climate classification updated. Meteorologische Zeitschrift:259-263. DOI: 10.1127/09412948/2006/0130.

Lechowicz MJ. 1995. Seasonality of flowering and fruiting in temperate forest trees. Canadian Journal of Botany 73:175-182. DOI: 10.1139/b95-021.

Li F, Sutton PC, Anderson SJ, Nouri H. 2017. Planning green space in Adelaide city: enlightenment from green space system planning of Fuzhou city (2015-2020). Australian Planner 54:126-133. DOI: 10.1080/07293682.2017.1345962.

Mahr S. 2014.Plant Flowers to Encourage Beneficial Insects. Available at https://wimastergardener.org/article/plant-flowers-to-encourage-beneficial-insects/ (accessed October 30, 2020).

Majewska AA, Altizer S. 2020. Planting gardens to support insect pollinators. Conservation Biology 34:15-25. DOI: 10.1111/cobi.13271.

Mathiasson ME, Rehan SM. Wild bee declines linked to plant-pollinator network changes and plant species introductions. Insect Conservation and Diversity n/a. DOI: 10.1111/icad.12429.

Matteson KC, Langellotto GA. 2011. Small scale additions of native plants fail to increase beneficial insect richness in urban gardens. INSECT CONSERVATION AND DIVERSITY 4:89-98. DOI: $10.1111 / \mathrm{j} .1752-4598.2010 .00103 . x$.

Milesi C, Running S, Elvidge C, Dietz JB, Tuttle B, Nemani R. 2005. Mapping and Modeling the Biogeochemical Cycling of Turf Grasses in the United States. Environmental management. DOI: 10.1007/S00267-004-0316-2.

Momol E, Tolbert J. 2019.Questions and Answers: 2009 Florida-Friendly Landscaping? Legislation. Available at https:/ledis.ifas.ufl.edu/ep440 (accessed August 3, 2020).

National Plant Data Team. 2020.The PLANTS Database. Available at http://plants.usda.gov

Peer) reviewing PDF | (2020:08:52066:2:0:NEW 20 Feb 2021) 
765 O’Connor RS, Kunin WE, Garratt MPD, Potts SG, Roy HE, Andrews C, Jones CM, Peyton JM,

766

767

768

769

770

771

772

773

774

775

776

777

778

779

780

781

782

783

784

785

786

787

788

789

790

791

792

793

794

795

796

797

798

799

800

801

802

803

804 Savage J, Harvey MC, Morris RKA, Roberts SPM, Wright I, Vanbergen AJ, Carvell C. 2019. Monitoring insect pollinators and flower visitation: The effectiveness and feasibility of different survey methods. Methods in Ecology and Evolution 10:2129-2140. DOI: 10.1111/2041-210X.13292.

Ohashi K, Yahara T. 2002. Visit larger displays but probe proportionally fewer flowers: counterintuitive behaviour of nectar-collecting bumble bees achieves an ideal free distribution. Functional Ecology 16:492-503. DOI: https://doi.org/10.1046/j.13652435.2002.00644.x.

Pardee GL, Philpott SM. 2014. Native plants are the bee's knees: local and landscape predictors of bee richness and abundance in backyard gardens. Urban Ecosystems 17:641-659. DOI: 10.1007/s11252-014-0349-0.

Penn State Extension. 2019. Why Use Native Plants? Available at https://extension.psu.edu/whyuse-native-plants (accessed August 3, 2020).

Philpott SM, Albuquerque S, Bichier P, Cohen H, Egerer MH, Kirk C, Will KW. 2019. Local and Landscape Drivers of Carabid Activity, Species Richness, and Traits in Urban Gardens in Coastal California. Insects 10:112. DOI: 10.3390/insects10040112.

Piano E, Souffreau C, Merckx T, Baardsen LF, Backeljau T, Bonte D, Brans KI, Cours M, Dahirel M, Debortoli N, Decaestecker E, De Wolf K, Engelen JMT, Fontaneto D, Gianuca AT, Govaert L, Hanashiro FTT, Higuti J, Lens L, Martens K. 2020. Urbanization drives cross-taxon declines in abundance and diversity at multiple spatial scales. Global Change Biology 26:1196-1211. DOI: 10.1111/gcb.14934.

Potts SG, Biesmeijer JC, Kremen C, Neumann P, Schweiger O, Kunin WE. 2010. Global pollinator declines: trends, impacts and drivers. Trends in Ecology \& Evolution 25:345-353. DOI: $10.1016 /$ j.tree.2010.01.007.

Richards RT, Chambers JC, Ross C. 1998. Use of native plants on federal lands: policy and practice. Rangeland Ecology \& Management / Journal of Range Management Archives 51:625-632.

Salisbury A, Armitage J, Bostock H, Perry J, Tatchell M, Thompson K. 2015. EDITOR'S CHOICE: Enhancing gardens as habitats for flower-visiting aerial insects (pollinators): should we plant native or exotic species? Journal of Applied Ecology 52:1156-1164. DOI: 10.1111/1365-2664.12499.

Sánchez-Bayo F, Wyckhuys KAG. 2019. Worldwide decline of the entomofauna: A review of its drivers. Biological Conservation 232:8-27. DOI: 10.1016/j.biocon.2019.01.020.

Sandström UG, Angelstam P, Mikusiński G. 2006. Ecological diversity of birds in relation to the structure of urban green space. Landscape and Urban Planning 77:39-53. DOI: 10.1016/j.landurbplan.2005.01.004.

Shimadzu H, Dornelas M, Henderson PA, Magurran AE. 2013. Diversity is maintained by seasonal variation in species abundance. BMC Biology 11:98. DOI: 10.1186/1741-7007-11$\underline{98}$. 
805 Sleeter BM, Wilson T, Sharygin E, Sherba JT. 2017. Future scenarios of land change based on

806

807

808

809

810

811

812

813

814

815

816

817

818

819

820

821

822

823

824

825

826

827

828

829

830

831

832

833

834

835

836

837

838

839

840

841

842

843

844 empirical data and demographic trends. Earth's Future 5:10681083. DOI: 10.1002/2017EF000560.

Smith RM, Gaston KJ, Warren PH, Thompson K. 2006. Urban domestic gardens (VIII) : environmental correlates of invertebrate abundance. Biodiversity and Conservation 15:2515-2545. DOI: $10.1007 / \mathrm{s} 10531-005-2784-\mathrm{y}$.

Smith B, Wilson JB. 1996. A Consumer's Guide to Evenness Indices. Oikos 76:70-82. DOI: $10.2307 / 3545749$.

Southon GE, Jorgensen A, Dunnett N, Hoyle H, Evans KL. 2017. Biodiverse perennial meadows have aesthetic value and increase residents' perceptions of site quality in urban green-space. Landscape and Urban Planning 158:105-118. DOI: 10.1016/j.landurbplan.2016.08.003.

Staab M, Pereira-Peixoto MH, Klein A-M. 2020. Exotic garden plants partly substitute for native plants as resources for pollinators when native plants become seasonally scarce. Oecologia 194:465-480. DOI: $10.1007 / \mathrm{s} 00442-020-04785-8$.

Stanley AG, Kaye TN, Dunwiddie PW. 2011. Multiple Treatment Combinations and Seed Addition Increase Abundance and Diversity of Native Plants in Pacific Northwest Prairies. Ecological Restoration 29:35-44. DOI: 10.3368/er.29.1-2.35.

Stavert J, Bartomeus I, Beggs J, Gaskett A, Pattemore D, Stavert C. 2019. Plant species dominance increases pollination complementarity and plant reproductive function. Ecology 100. DOI: $10.1002 /$ ecy.2749.

Theodorou P, Albig K, Radzevičiūtè R, Settele J, Schweiger O, Murray TE, Paxton RJ. 2017. The structure of flower visitor networks in relation to pollination across an agricultural to urban gradient. Functional Ecology 31:838-847. DOI: 10.1111/1365-2435.12803.

Threlfall CG, Williams NSG, Hahs AK, Livesley SJ. 2016. Approaches to urban vegetation management and the impacts on urban bird and bat assemblages. Landscape and Urban Planning 153:28-39. DOI: 10.1016/j.landurbplan.2016.04.011.

Todorova A, Asakawa S, Aikoh T. 2004. Preferences for and attitudes towards street flowers and trees in Sapporo, Japan. Landscape and Urban Planning 69:403-416. DOI: 10.1016/j.landurbplan.2003.11.001.

UF/IFAS Florida-Friendly Landscaping Program.Florida-Friendly Landscaping ${ }^{\mathrm{TM}}$ Program University of Florida, Institute of Food and Agricultural Sciences. Available at https://ffl.ifas.ufl.edu/ (accessed June 29, 2020).

United Nations, Department of Economic and Social Affairs, Population Division. 2019. World urbanization prospects: 2018 : highlights.

Vrdoljak SM, Samways MJ, Simaika JP. 2016. Pollinator conservation at the local scale: flower density, diversity and community structure increase flower visiting insect activity to mixed floral stands. Journal of Insect Conservation 20:711-721. DOI: 10.1007/s10841-016-9904$\underline{8}$.

Westphal C, Bommarco R, Carré G, Lamborn E, Morison N, Petanidou T, Potts SG, Roberts SPM, Szentgyörgyi H, Tscheulin T, Vaissière BE, Woyciechowski M, Biesmeijer JC, 
845

846

847

848

849

850

851

852

853

854

855

856

857

858

859

860

861

862

863

864

865

866

867

868

869

870

871

872

873

874

875

876

877

878

879

880

881

882

883

884

Kunin WE, Settele J, Steffan-Dewenter I. 2008. Measuring Bee Diversity in Different European Habitats and Biogeographical Regions. Ecological Monographs 78:653-671. DOI: https://doi.org/10.1890/07-1292.1.

Williams NM, Ward KL, Pope N, Isaacs R, Wilson J, May EA, Ellis J, Daniels J, Pence A, Ullmann K, Peters J. 2015. Native wildflower plantings support wild bee abundance and diversity in agricultural landscapes across the United States. Ecological Applications 25:2119-2131. DOI: 10.1890/14-1748.1.

Williams NM, Winfree R. 2013. Local habitat characteristics but not landscape urbanization drive pollinator visitation and native plant pollination in forest remnants. Biological Conservation 160:10-18. DOI: 10.1016/j.biocon.2012.12.035.

Wolda H. 1988. Insect Seasonality: Why? Annual Review of Ecology and Systematics 19:1-18. DOI: $10.1146 /$ annurev.es.19.110188.000245.

Wright MG, Samways MJ. 1998. Insect species richness tracking plant species richness in a diverse flora: gall-insects in the Cape Floristic Region, South Africa. Oecologia 115:427433. DOI: $10.1007 / \mathrm{s} 004420050537$.

\section{References for Plant Identification}

Wunderlin RP, 1939-, Hansen BF. 2003. Guide to the vascular plants of Florida. University Press of Florida.

\section{References for Insect Identification}

Arnett RH, Thomas MC. 2000. American Beetles, Volume I: Archostemata, Myxophaga, Adephaga, Polyphaga: Staphyliniformia.

Arnett RH, Thomas MC, Skelley PE, Frank HJ. 2002. American Beetles, Volume II: Polyphaga: Scarabaeoidea through Curculio.

Evans AV. 2014. Beetles of Eastern North America. Princeton \&University Press.

Goulet H, Hubert JF. 1993. Hymenoptera of the world. An identification guide to families. Ottawa: Research Branch, Agricultural Canada Publication. Canada Communication GroupPublishing.

Iowa State University Department of Entomology. Welcome to BugGuide.Net! Available at https://bugguide.net/node/view/15740 (accessed October 30, 2020).

McAlpine JF (ed.). 1987. Manual of Nearctic Diptera. Ottawa, Ontario: Biosystematics Research Centre.

Newton A. 1997. Review of Agyrtidae (coleoptera), with a New Genus and species from New Zealand. Annales Zoologici 47:111-156.

Smithsonian National Museum of Natural History.Encyclopedia of Life. Available at https://naturalhistory.si.edu/research/eol (accessed November 27, 2020).

Triplehorn CA, Johnson NF, Borror DJ. 2005. Borror and DeLong's introduction to the study of insects. Belmont, CA: Thompson Brooks/Cole. 
885 Willemstein SC. 1987. An evolutionary basis for pollination ecology. Leiden: E.J. Brill.

886

887

888 


\section{Figure 1}

Cumulative bloom count by most common plant species

Figure 1 displays the cumulative bloom count for each plant throughout the course of the study. The top dozen species of plants dominated bloom counts by both number (see lefthand y-axis label) and percentage (see right-hand y-axis label). 


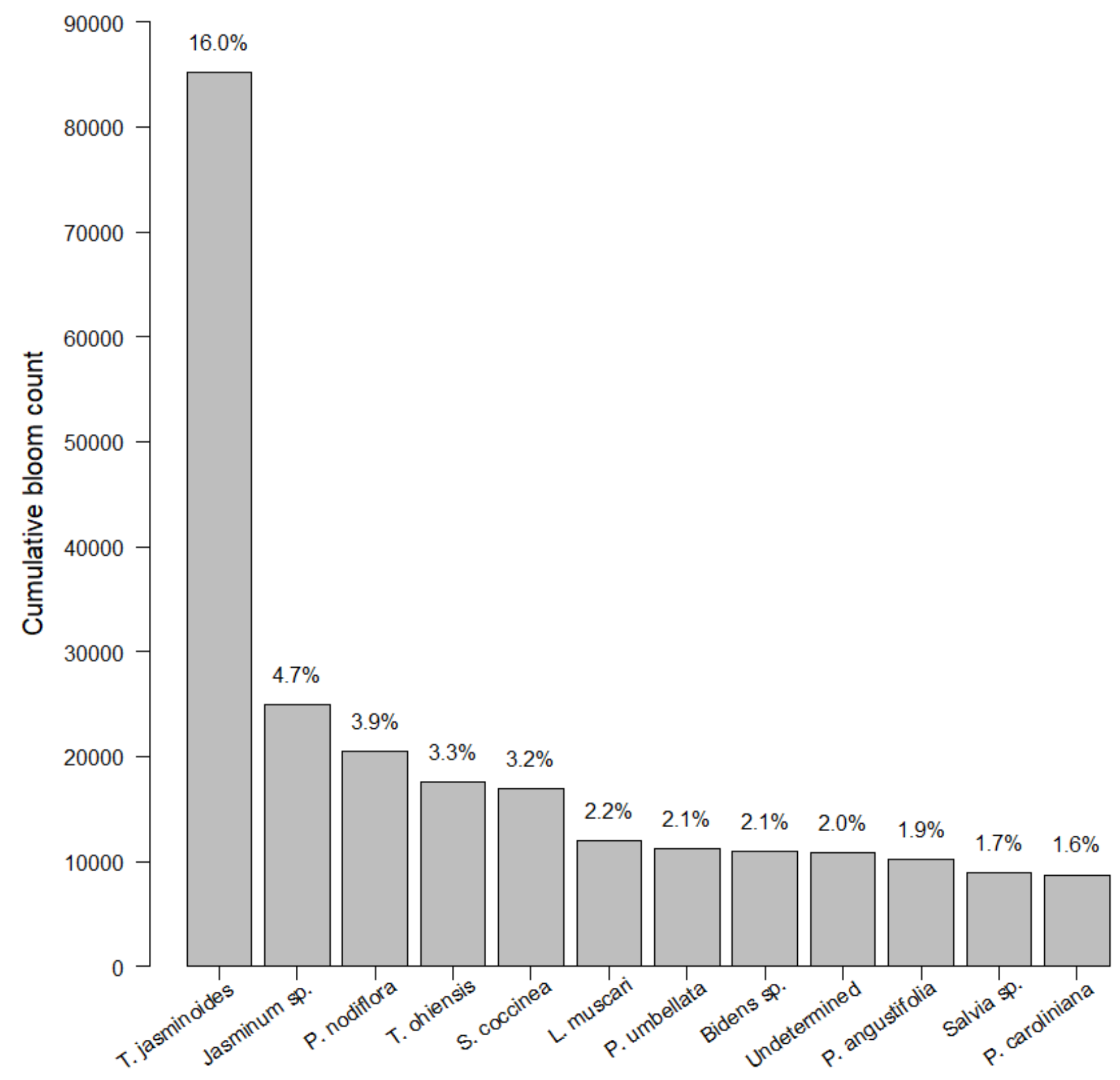


Figure 2

Insect abundance by order

Figure 2 displays the total summed insects counted for each order throughout the course of the study. The left-hand y-axis displays the count while the right-hand $y$-axis displays the percentage. 


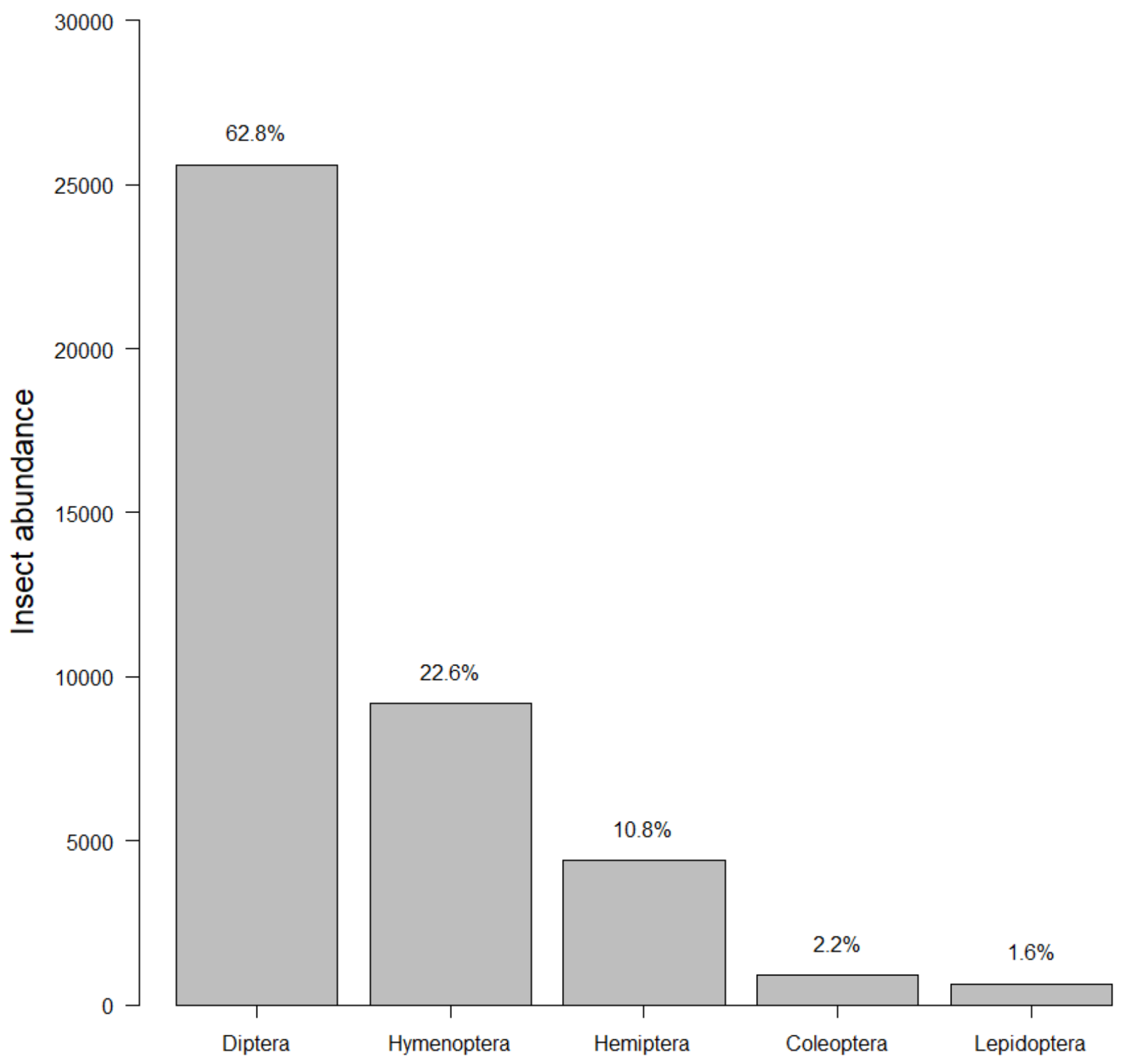


Figure 3

Correlation between dependent variables and bloom abundance

Scatterplots of the relationship between total bloom abundance (per site, per day) and A) total insect abundance; B) total insect richness; C) flower visitor abundance; D) flower visitor richness. 

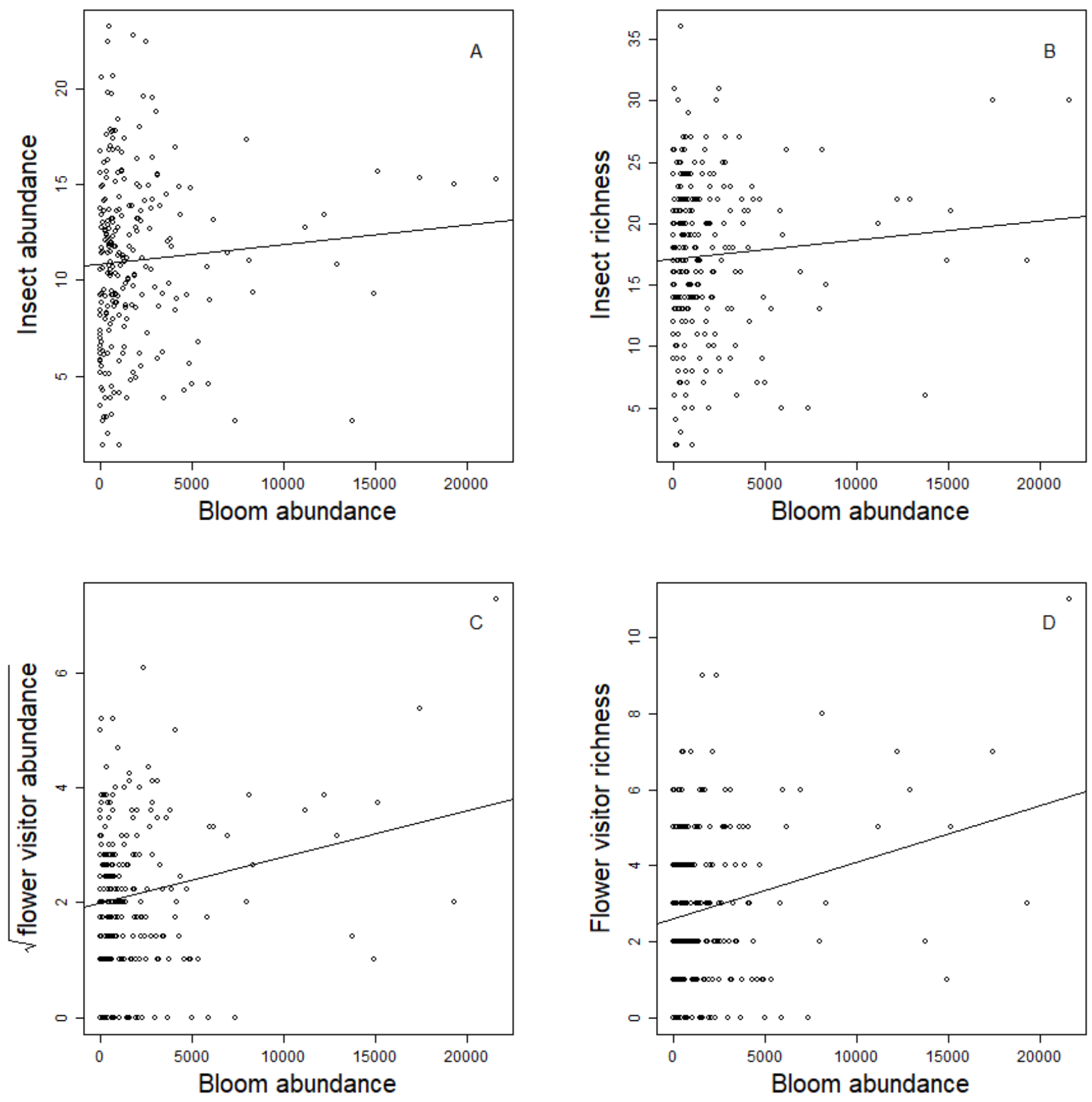


\section{Figure 4}

Interaction between bloom abundance and bloom eveness for $\mathrm{y}=\mathrm{sqrt}$ (Insect Abundance).

On the $x$-axis is bloom abundance (in number of blooms) from 0 to 30,000 blooms. The bloom abundance axes were capped at 30,000 to make the graph easier to read. On the y-axis is the square root of insect abundance counted at each site per day. On the z-axis is bloom evenness, measured by Evar from 0 to 1.0, where $0.0=$ no evenness and $1.0=$ a perfectly even community. This graph indicates that bloom abundance alone did not have a clear correlation to insect abundance when evenness was low. However, as evenness increased, bloom abundance showed a strong and positive correlation with insect abundance. 


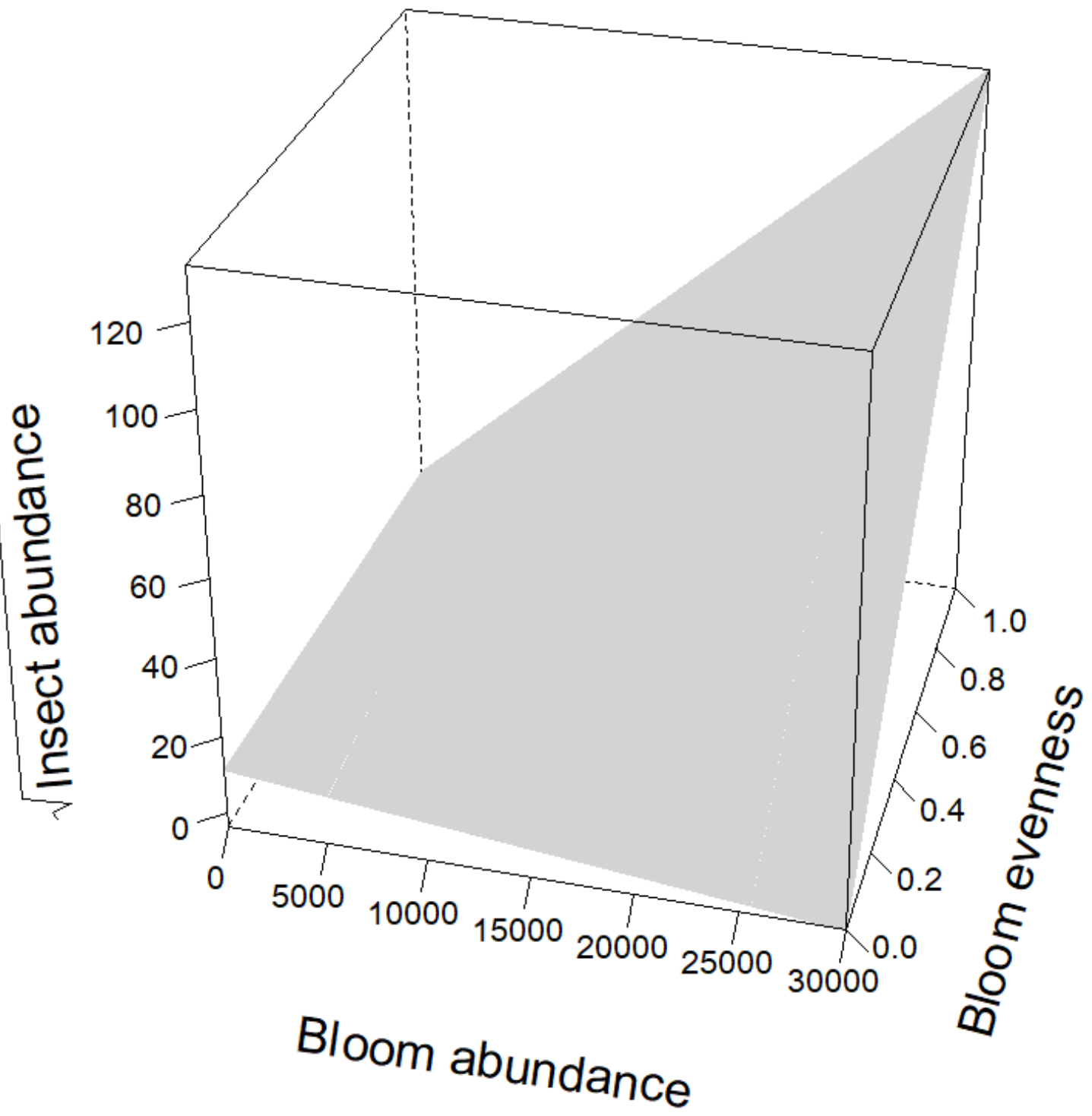




\section{Figure 5}

Interaction term between bloom abundance and bloom evenness for $\mathrm{y}=$ insect richness).

On the x-axis is bloom abundance (in number of blooms) from 0 to 30,000 blooms. The bloom abundance axes were capped at 30,000 to make the graph easier to read. On the y-axis is total insect richness (the number of separate species of insects) counted at each site per day. On the $z$-axis is bloom evenness, measured by Evar from 0 to 1.0, where $0.0=$ no evenness and $1.0=$ a perfectly even community. This graph indicates that bloom abundance alone did not have a clear correlation to insect richness when evenness was low. However, as evenness increased, bloom abundance showed a strong and positive correlation with insect abundance. 


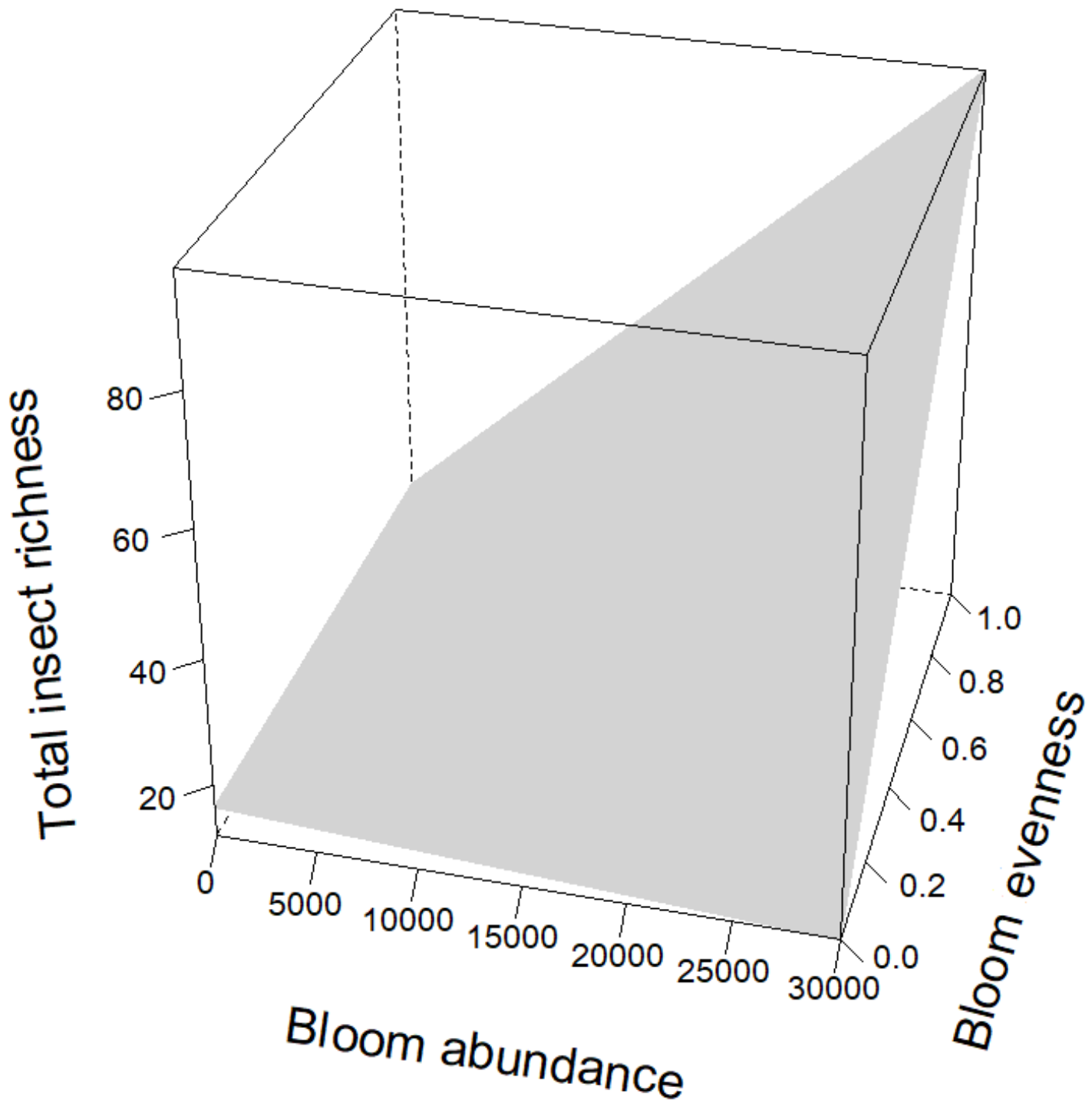




\section{Table 1 (on next page)}

Table 1: Model selection statistics for the garden variables and landscape factors affecting four measures of insect community: (a) Insect Abundance, (b) Insect Richness, (c) Flower-visiting Insect Abundance, (d) Flower-visiting Insect Richness

The models tested were general linear mixed models, with the exception of (d) Flower-visiting Insect Richness, which was a generalized linear mixed Poisson model. Abundance of Flower-visiting Insects and Insect Abundance were square root transformed. We tested seven to twelve models for each response variable. The top three models (or however many resulted in an AICc cumulative weight of $90 \%$ ) for each response are listed below.

Plus signs indicate that a positive relationship was found, while negative signs indicate a negative relationship. Blank spaces indicate a lack of statistically significant relationships ( $p>0.05)$.

Each model ended with the code, "random

$\sim 1 \mid$ Site.name/Date.veg.survey/Date.bowl.survey/bloom.date/Date.veg.survey/Date.bowl.survey/bloom.date, method = "ML", which added the mixed effects of site location and sample dates. The exception was the Poisson model for (d) Flower-visiting Insect Richness, whose syntax required additional parentheses and did not include sample dates due to model singularity errors.

Citation: https://besjournals.onlinelibrary.wiley.com/doi/full/10.1111/1365-2435.12803

Key

$\mathrm{K}=$ number of parameters in the model

d.f. $=$ degrees of freedom

AICc $=$ Akaike weights

Delta AICC $=$ Change in Akaike weights

$w_{i}=$ Akaike weights $c w_{i}=$ cumulative Akaike weights

$\log L=\log$ likelihood 


\begin{tabular}{|c|c|c|c|c|c|c|c|c|c|c|c|c|c|c|c|c|c|}
\hline $\begin{array}{l}\text { Response } \\
\text { (model) }\end{array}$ & $\mathbf{K}$ & d.f. & AICc & $\triangle \mathrm{AICC}$ & $w_{i}$ & $c w_{i}$ & $\begin{array}{l}\text { Bloom } \\
\text { Abundance }\end{array}$ & $\begin{array}{l}\text { Plant } \\
\text { Richness }\end{array}$ & $\begin{array}{l}\text { Fl. } \\
\text { friendly } \\
\text { plant } \\
\text { richness }\end{array}$ & $\begin{array}{l}\text { Native } \\
\text { plant } \\
\text { richness }\end{array}$ & $\begin{array}{l}\text { Nonnative } \\
\text { plant } \\
\text { richness }\end{array}$ & $\begin{array}{l}\text { Fl. Friendly } \\
\text { bloom } \\
\text { abundance }\end{array}$ & $\begin{array}{l}\text { Native } \\
\text { bloom } \\
\text { abundance }\end{array}$ & $\begin{array}{l}\text { Nonnative } \\
\text { bloom } \\
\text { abundance }\end{array}$ & $\begin{array}{l}\text { Bloom } \\
\text { evenness }\end{array}$ & $\begin{array}{l}\text { Bloom } \\
\text { abundance*bloom } \\
\text { evenness }\end{array}$ & $\begin{array}{l}\text { Bloom } \\
\text { richness }\end{array}$ \\
\hline \multicolumn{18}{|l|}{$\begin{array}{l}\text { (a) Insect } \\
\text { Abundance }\end{array}$} \\
\hline & 10 & 209 & 526.24 & 0.00 & 0.99 & 0.99 & & - & & & & & & & & + & \\
\hline & 13 & 206 & 537.21 & 10.97 & 0.00 & 1.00 & + & & & - & & & & & & & \\
\hline & 8 & 211 & 539.07 & 12.83 & 0.00 & 1.00 & & - & & & & & & & & & \\
\hline \multicolumn{18}{|l|}{$\begin{array}{l}\text { (b) Insect } \\
\text { Richness }\end{array}$} \\
\hline & 10 & 209 & 1616.24 & 0.00 & 0.35 & 0.35 & & - & & & & & & & & + & \\
\hline & 9 & 210 & 1616.57 & 0.33 & 0.29 & 0.64 & & & & - & + & & & & & & \\
\hline & 8 & 211 & 1618.52 & 2.28 & 0.11 & 0.75 & & - & & & & & & & & & \\
\hline & 9 & 210 & 1619.18 & 2.94 & 0.08 & 0.83 & + & - & & & & & & & & & \\
\hline & 7 & 212 & 1619.62 & 3.38 & 0.06 & 0.90 & & - & & & & & & & & & \\
\hline $\begin{array}{l}\text { (c) Flower- } \\
\text { visiting } \\
\text { Insect }\end{array}$ & & & & & & & & & & & & & & & & & \\
\hline
\end{tabular}

1 Table 1: Model selection statistics for the garden variables and landscape factors affecting four measures of insect community: (a) Insect Abundance, (b) Insect Richness, (c) Flower-visiting Insect Abundance, (d) Flower-visiting Insect Richness

The models tested were general linear mixed models, with the exception of (d) Flower-visiting Insect Richness, which was a generalized linear mixed Poisson model. Abundance of Flower-visiting Insects and Insect Abundance were square root transformed. We tested seven to twelve models for each response variable. The top three models (or however many resulted in an AICc cumulative weight of $90 \%$ ) for each response are listed below.

Plus signs indicate that a positive relationship was found, while negative signs indicate a negative relationship. Blank spaces indicate a lack of statistically significant relationships $(\mathrm{p}>0.05)$.

\section{Each model ended with the code, "random}

$\sim$ I|Site.name/Date.veg.survey/Date.bowl.survey/bloom.date/Date.veg.survey/Date.bowl.survey/bloom.date, method = "ML", which added the mixed effects of site location and sample dates. The exception was the Poisson model for (d) Flower-visiting Insect Richness, whose syntax required additional parentheses and did not include sample dates due to model singularity errors.

Citation: https://besjournals.onlinelibrary.wiley.com/doi/full/10.1111/1365-2435.12803 


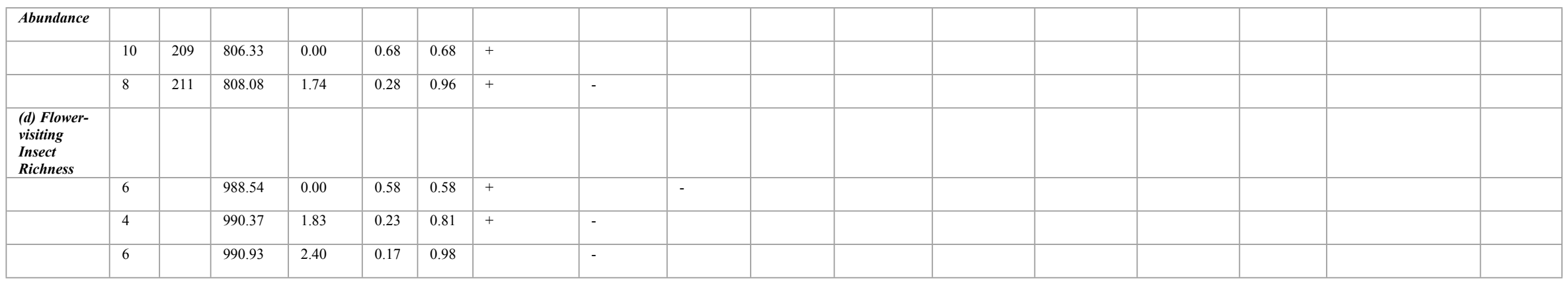

20

21

22

23 Key

24

$25 \mathrm{~K}=$ number of parameters in the model

26 d.f. = degrees of freedom

27 AICc $=$ Akaike weights

28 Delta AICc $=$ Change in Akaike weights

$29 w_{i}=$ Akaike weights

$30 \quad c w_{i}=$ cumulative Akaike weights

$31 \log L=\log$ likelihood. 


\section{Table 2 (on next page)}

Table 2: Coefficients and relative coefficient importance for models analyzing the following response variables: (a) Insect Abundance, (b) Insect Richness, (c) Flowervisiting Insect Abundance, (d) Flower-visiting Insect Richness

The models tested were general linear mixed models. Abundance of Flower-visiting Insects and Insect Abundance were square root transformed. We tested seven to twelve models for each response variable. The coefficients of the top model for each response variable is listed below.

Std. Error $=$ Standard Error

Pearson's $r$ = Pearson's $r$ (a measurement of relative importance. Higher numbers indicate greater importance) 
Table 2: Coefficients and relative coefficient importance for models analyzing the following response variables: (a) Insect Abundance, (b) Insect Richness, (c) Flower-visiting Insect Abundance, (d) Flower-visiting Insect Richness

The models tested were general linear mixed models. Abundance of Flower-visiting Insects and Insect Abundance were square root transformed. We tested seven to twelve models for each response variable. The coefficients of the top model for each response variable is listed below.

\begin{tabular}{|l|l|l|l|l|l|}
\hline Response (model) & Value & Std. Error & t-value & p-value & Pearson's r \\
\hline (a) Insect Abundance & & & & & \\
\hline (Intercept) & 3.413 & 0.098 & 34.853 & $0.000^{* * *}$ & - \\
\hline Plant Richness & -0.014 & 0.003 & -4.031 & $0.0001^{* * *}$ & -0.157 \\
\hline
\end{tabular}




\begin{tabular}{|c|c|c|c|c|c|}
\hline Bloom Abundance & -0.000 & 0.000 & -2.974 & $0.003 * *$ & 0.072 \\
\hline Bloom Evenness & -0.272 & 0.282 & -0.966 & 0.335 & -0.130 \\
\hline $\begin{array}{l}\text { Bloom Abundance*Bloom } \\
\text { Evenness }\end{array}$ & 0.001 & 0.000 & 4.132 & $0.0001 * * *$ & 0.137 \\
\hline \multicolumn{6}{|l|}{ (b) Insect Richness } \\
\hline (Intercept) & 17.69 & 0.936 & 18.900 & $0.000 * * *$ & -- \\
\hline Plant Richness & -0.117 & 0.031 & -3.747 & $0.0002 * * *$ & -0.143 \\
\hline Bloom Abundance & 0.000 & 0.000 & -1.058 & 0.291 & 0.077 \\
\hline Bloom Evenness & 3.402 & 2.542 & 1.338 & 0.182 & 0.016 \\
\hline $\begin{array}{l}\text { Bloom Abundance*Bloom } \\
\text { Evenness }\end{array}$ & 0.006 & 0.003 & 2.267 & $0.024 *$ & 0.101 \\
\hline \multicolumn{6}{|l|}{$\begin{array}{l}\text { (c) Flower-visiting Insect } \\
\text { Abundance }\end{array}$} \\
\hline (Intercept) & 2.323 & 0.175 & 13.295 & $0.000 * * *$ & -- \\
\hline Bloom Abundance & 0.0001 & 0.000 & 3.958 & $0.0001 * * *$ & 0.198 \\
\hline $\begin{array}{l}\text { Florida Friendly plant } \\
\text { richness }\end{array}$ & -0.085 & 0.032 & -2.662 & $0.008 * * *$ & -0.095 \\
\hline Native plant richness & -0.025 & 0.030 & -0.831 & 0.407 & -0.058 \\
\hline Non-native plant richness & 0.046 & 0.027 & 1.691 & 0.092 & -0.061 \\
\hline \multicolumn{6}{|l|}{$\begin{array}{l}\text { (d) Flower-visiting Insect } \\
\text { Richness }\end{array}$} \\
\hline (Intercept) & 3.192 & 0.271 & 11.792 & $0.000 * * *$ & -- \\
\hline Bloom Abundance & 0.000 & 0.000 & 4.732 & $0.000 * * *$ & 0.233 \\
\hline $\begin{array}{l}\text { Florida Friendly plant } \\
\text { richness }\end{array}$ & -0.142 & 0.050 & -2.869 & $0.005 * * *$ & -0.122 \\
\hline Native plant richness & -0.029 & 0.046 & -0.626 & 0.532 & -0.062 \\
\hline Non-native plant richness & 0.057 & 0.042 & 1.370 & 0.172 & -0.081 \\
\hline
\end{tabular}


33 Key

34

35

36 Pearson's $r$ = Pearson's $r$ (a measurement of relative importance. Higher numbers indicate greater importance) 